\title{
Aspectos geoambientais, uso e ocupação do solo na Bacia do Rio Carnaíba de
} Dentro - BA

\section{Geoenvironmental aspects, use and occupation of soil in the river basin Carnaíba de Dentro - BA}

\section{Aspectos Geo ambientales, uso y ocupación del suelo en la cuenca del río Carnaíba de Dentro - BA}

Jane Mary Lima Castro ${ }^{1}$ http://orcid.org/0000-0002-9887-0113 Meirilane Rodrigues Maia 2 http://orcid.org/0000-0001-8757-0601

\footnotetext{
Universidade Estadual do Sudoeste Bahia-UESB/Secretaria Municipal de Educação; Guanambi-Bahia-Brasil; e-mail: janecastroo@hotmail.com

2 Universidade Estadual do Sudoeste Bahia/Programa de Pós-Graduação em Geografia - PPGEO-UESB-Bahia-Brasil, e-mail: meire.rmaia@gmail.com..
}

Recebido em: 01/12/2020

Aceito para publicação em: 20/03/2021

\section{Resumo}

Este artigo discute a dinâmica do uso do solo na bacia do rio Carnaíba de Dentro - Bahia, bem como diagnosticar suas interações socioambientais. Os procedimentos metodológicos compreenderam elaboração de mapa temático; trabalho de campo e análise de dados. Os resultados da pesquisa retrataram uma problemática socioambiental com inferências da intervenção humana para a degradação ambiental da área de estudo como: desmatamento, represamento da água, resíduos sólidos e efluentes urbanos, queimadas, poluição do ar, água e solo, esgotamento sanitário, exploração mineral, uso de agrotóxicos, aterramentos de rios e lagoas, ocupação humana irregular e desordenada nas margens dos rios, compactação e impermeabilização do solo por meio da construção da ferrovia, parque eólico e barragem de rejeitos da Bahia Mineração (BAMIN).

Palavras-chave: Desmatamento. Compactação e impermeabilização do solo. Ocupação humana. Aterramentos de lagoas.

\footnotetext{
Abstract

This article discusses the dynamics of land use in the Carnaíba de Dentro - Bahia, river basin, as well as diagnosing its socio-environmental interactions. The methodological procedures included the elaboration of a thematic map; fieldwork and data analysis. The research results portrayed a
} 
socio-environmental problem with inferences of human intervention for the environmental degradation of the study area, such as: deforestation, water impoundment, solid residues and urban effluents, fires, air pollution, water and soilsanitary sewage, mineral exploration, use of pesticides, landings of rivers and lakes, irregular and disordered human occupation on the banks of rivers, compaction and waterproofing of the soil through the construction of the railroad, wind farm and tailings dam of Bahia Mineração (BAMIN).

Keywords: Deforestation. Compaction and waterproofing of soil. Human Occupation. Pond landings.

\section{Resumen}

Em este artículo se analiza la dinámica de uso del suelo en la cuenca del río Carnaíba de Dentro Bahía, así como diagnosticar las interacciones socioambientales. Los procedimientos metodológicos comprendieron la elaboración de un mapa temático; trabajo de campo y análisis de datos. Los resultados de la pesquisa retrataron una problemática socioambiental con inferências de la intervención humana para la degradación ambiental del área de estudo, como: deforestación, embalse de agua, residuos sólidos y efluentes urbanos, quemadas, polución del aire, agua y suelo, agotamiento sanitário, exploración mineral, uso de pesticidas, soterramiento de ríos y lagunas, ocupación humana irregular y desordenada en las márgenes de los ríos, compactación e impermeabilización del suelo por medio de la construcción del ferrocarril, parque eólico y presa de relaves de Bahia Mineração ( BAMIN).

Palabras clave: Deforestación. Compactación e impermeabilización del suelo. Ocupación humana. Soterramiento de lagunas.

\section{Introdução}

A bacia do rio Carnaíba de Dentro está localizada, numa região semiárida, drenada por rios intermitentes e temporários. Está inserida, principalmente, no domínio da caatinga, apesar de abarcar três domínios vegetais diferentes, floresta estacional semidecidual com particularidades de vegetação endêmica e o cerrado. A área de estudo localiza-se na Região Sudoeste do Estado da Bahia e possui uma área total de aproximadamente $2.600 \mathrm{~km}^{2}$, abrangendo o município de Guanambi e Candiba, parte dos municípios de Caetité, Pindaí e Palmas de Monte Alto (Mapa 1).

O estudo dos aspectos geoambientais, o uso e ocupação do solo da bacia hidrográfica do Rio Carnaíba de Dentro - BA tem o propósito de discutir a dinâmica do uso do solo bem como diagnosticar suas interações socioambientais e caracterizálas a partir do conhecimento dessas interações por meio dos procedimentos 
metodológicos, que compreenderam elaboração de mapa temático; trabalho de campo (com aplicação de questionários, registro fotográfico, ficha de campo) análise de dados para promover o estudo dos impactos ambientais e sanar as lacunas de informações sobre a bacia, cujo padrão de drenagem contempla vários municípios circunvizinhos.

Mapa 1- Localização da Bacia do Rio Carnaiba de Dentro

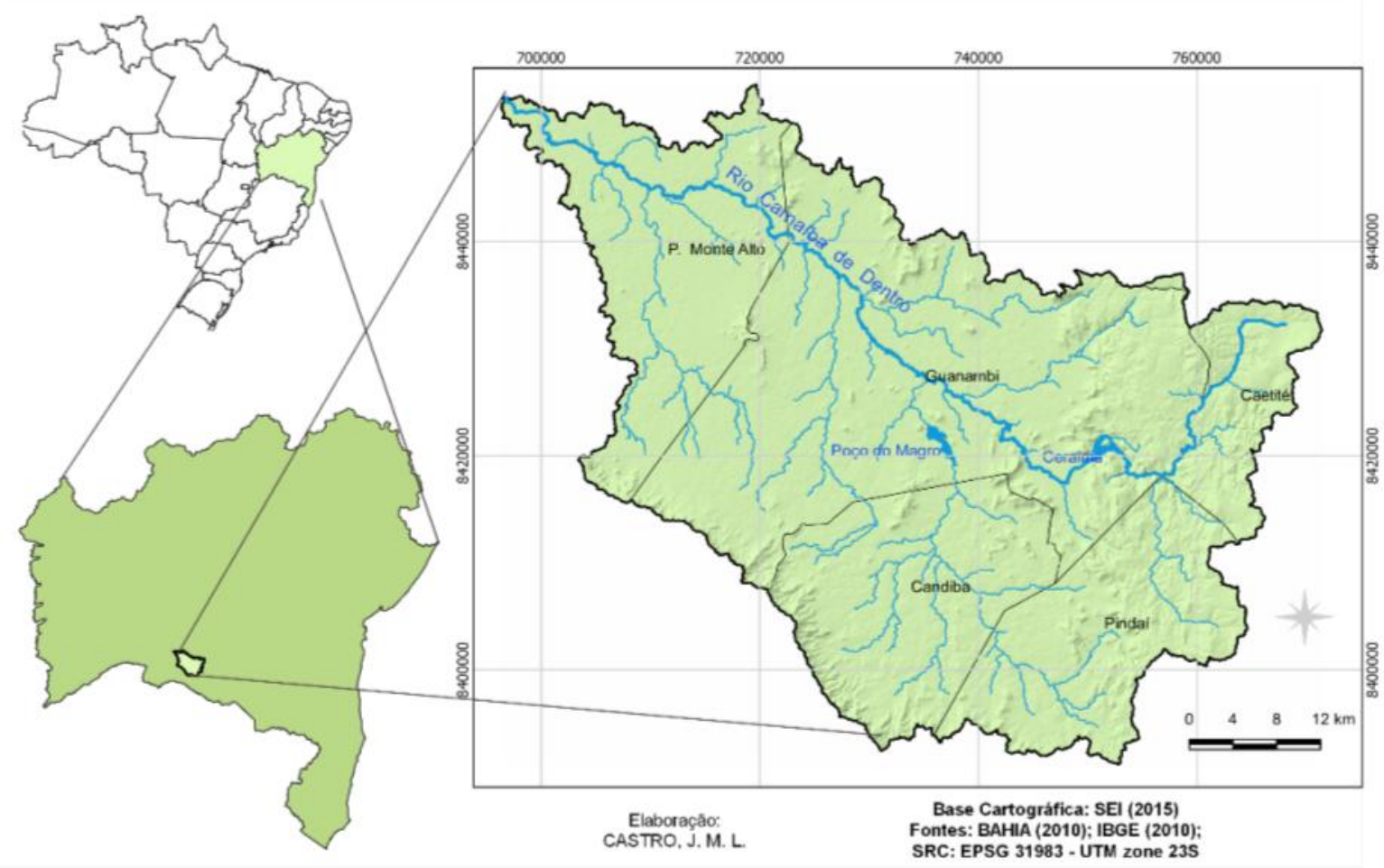

Fonte: Base Cartografica SEI, 2015. Elaboração: CASTRO, J. Maio, 2018.

As peculiaridades geoambientais da porção drenada pelo alto curso do rio Carnaíba de Dentro corresponde a compartimentos geomorfológicos de características ambientais próprias, uma vez que são áreas serranas da Serra Geral do Espinhaço e do Pediplano da Chapada Diamantina, de elevada altitude e potencialidades paisagísticas de ambientes quentes e úmidos. Nessa área evidenciam-se transformações ambientais, com dinâmica intensa nos processos de substituição de florestas por parque eólico, pastagens, nascentes de rios por barragens de rejeitos.

A porção drenada pelo médio e baixo curso do rio Carnaíba de Dentro, corresponde a uma extensa área plana, horizontalizada, de baixa altitude, caracterizada pelas Depressões Periféricas Interplanálticas, relevo plano e suavemente 
ondulado com presença de alguns inselbergs, que Ab'Saber (2003) caracteriza por morrotes do tipo inselberg ou agrupamento deles, e os qualificam por relevos residuais que resistiram aos velhos processos desnudacionais, responsáveis pelas superfícies aplanadas dos sertões, ao fim do Terciário e início do Quaternário.

\section{Uso e ocupação do solo na bacia do rio Carnaíba de Dentro - BA}

A organização espacial da bacia do rio Carnaíba de Dentro expõe a relação sociedade- natureza, num processo histórico de modificação, apropriação e exploração do uso dos recursos naturais, cujas transformações provocam impactos ambientais antropizados no meio físico, principalmente no solo.

Mapa 2- Uso, ocupação do solo e cobertura vegetal da bacia do rio Carnaíba de Dentro BA.
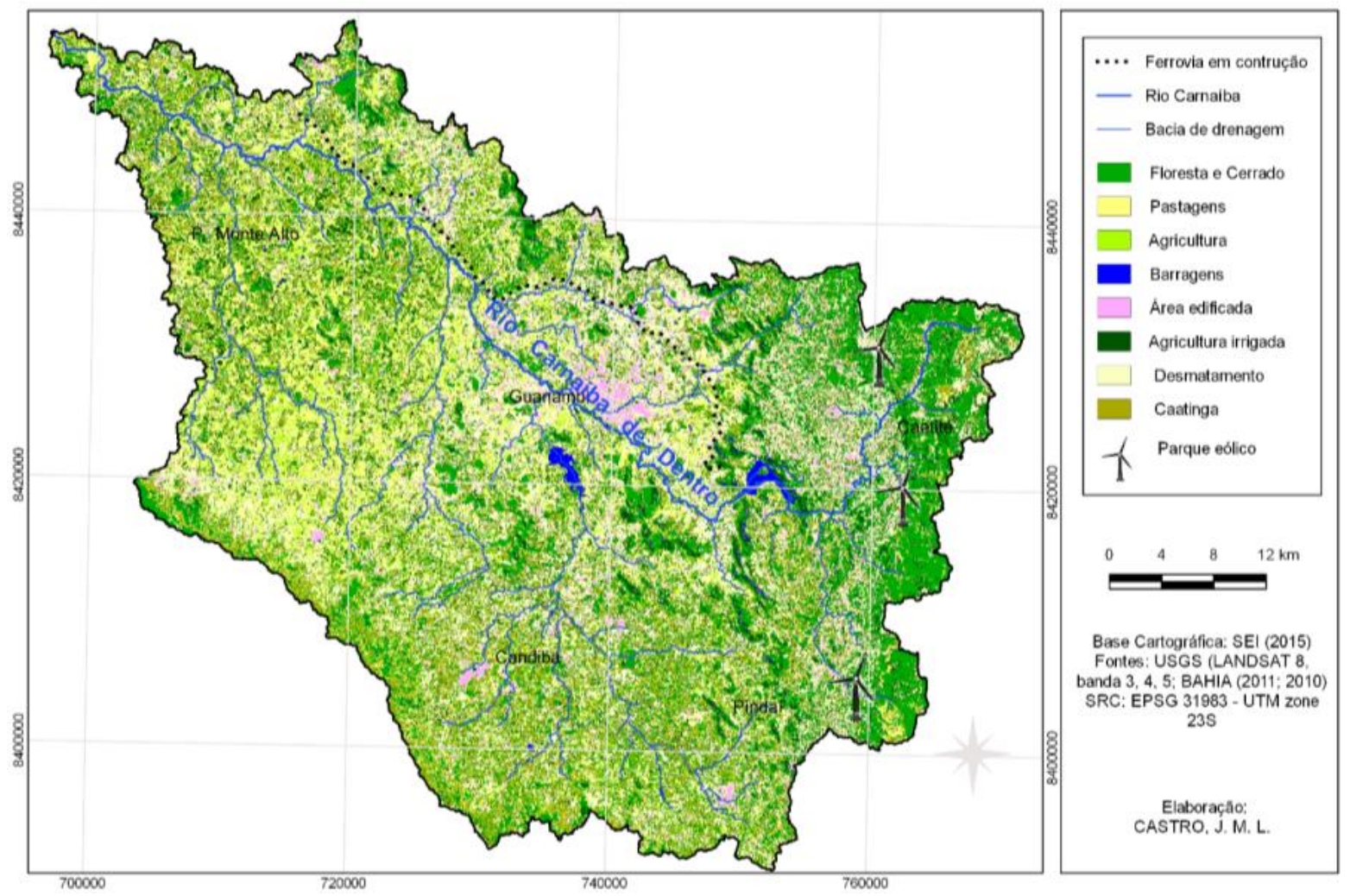

Fonte: Base Cartografica SEI, 2015. Elaboração: CASTRO, J. Setembro, 2018.

Para Drew (2011), os solos representam um extrato de todos os fatores do ambiente humano e o seu equilíbrio depende da dinamicidade entre o clima, os materiais de origem, a topografia, a biota e o tempo, fatores que determinam suas características. Dessa forma, o uso e a ocupação do solo na bacia do rio Carnaíba de 
Dentro estão sensivelmente alterados por meio dos processos físico-químicos ${ }^{3}$ e biológicos dos sistemas naturais. Observa-se, no mapa 2, que a atividade agrícola juntamente com as pastagens representa o principal uso do solo.

Considera-se que toda a região da bacia é usada para cultivo da agricultura de subsistência e para pastagens, mas nota-se que a área das depressões periféricas e interplanálticas domina essa condição de uso do solo. Entretanto, o potencial agrícola de uso dos solos nessa localidade é influenciado pelas características do clima semiárido.

$\mathrm{Na}$ agricultura sobressaem as culturas de ciclo rápido como feijão, mandioca, abóbora e milho. O algodão, cultura de ciclo médio, já foi destaque nos municípios de Guanambi e Palmas de Monte Alto, ainda é uma cultura ativa, mas produzida com cautela, devido as pragas da cotonicultura se desenvolverem intensamente no clima seco.

As áreas ocupadas por pastagens, pastos naturais ou antropizados, com cobertura dominante de espécies de gramíneas, denominado pasto sujo ou macega ${ }^{4}$ e formação de capins, são destinadas à pecuária extensiva para a criação de bovinos para a produção de carne e leite. Estas aparecem distribuídas em toda área de estudo, porém na região central e sudoeste da bacia elas se mostram de forma contínua. Numa proporção inferior cria-se também e ovinos e suínos.

Ressalta-se que algumas áreas antes usadas para pastagens, foram abandonadas e evoluíram para uma formação de macega ou capoeira rala, dependendo do tempo de abandono. Nota-se, também, que as atividades agropecuárias perderam sua importância, uma vez que, encontrou-se muitas casas e terrenos abandonados, novas oportunidades surgiam com o desenvolvimento da cidade e a população rural na busca por uma renda melhor, atraiu-se as áreas periféricas das cidades que compõem a área edificada da bacia, formando novos loteamentos e expandindo o crescimento urbano dessa área.

\footnotetext{
${ }^{3}$ Processos de modificação ou alteração do solo por meio da deterioração estrutural mecanizada (gradeação e aração), erosão, fertilizantes artificiais, agrotóxicos, irrigação (salinização e dessalinização). Intemperismo.

${ }^{4}$ Macega, vegetação rasteira que estão próximas às áreas em que ocorre a presença de vegetação arbustiva.
} 
Já a agricultura irrigada, está distribuída por toda a bacia, em pequenas hectares com padrões de produção bem distintos. $O$ pequeno produtor convive com a agricultura familiar para sustentar sua economia, principalmente nos trechos cimeiros de Morrinhos (divisa dos municípios de Caetité e Guanambi) e nos vales fluviais das barragens de Ceraíma e Poço do Magro onde são produzidas culturas predominantemente de ciclo rápido, como milho, batata doce, mandioca, banana, mamão, maracujina, tomate, verduras e hortaliças, dentre outras.

Percebe-se que a mecanização agrícola, mesmo nas áreas de culturas irrigadas, é pouco utilizada, restringe-se apenas em gradear o solo para o plantio. Já os usos de fertilizantes de defensivos agrícolas são utilizados em grandes quantidades e periodicidade sequencial ao bom desenvolvimento do produto agricultável. Segundo entrevista com os produtores de verduras e hortaliças, tem cultura que necessita de agrotóxico toda semana.

Drew (2011) assinala que a atividade agrícola modifica consideravelmente o solo e representa a tentativa mais generalizada de controle do ambiente humano, uma vez que

a função primordial da agricultura é a manipulação dos ecossistemas naturais a fim de elevar ao máximo a produção de gêneros alimentícios (energia). Quanto mais sofisticada a forma da agricultura, mais deformados se tornam os ecossistemas naturais e maior a proporção do fluxo de energia do sistema que escoa para o uso humano (DREW, 2011, p. 145).

Em função da atividade agrícola nota-se que há desmatamento em toda a bacia. A região, a qual a cobertura vegetal é a caatinga, a vegetação foi quase toda desmatada, resta pequenas manchas da vegetação espalhada. Nas encostas íngremes da bacia e área serrana o desmatamento também é visível. Existem manchas de remanescentes florestais espalhada por toda área da bacia e na parte planáltica essa cobertura vegetal ainda é expressiva, há grande parte da floresta estacional semidecidual e do cerrado. A nascente do rio Carnaíba de Dentro encontra-se aparentemente protegida. 
Entretanto, há um agrave referente ao desmatamento na bacia do rio Carnaíba de Dentro. No município de Palmas de Monte Alto, o extrativismo vegetal da lenha para produção de carvão, desmatou muitos hectares de mata da caatinga num passado recente, inclusive a mata ciliar do rio.

Milhões de metros cúbicos de carvão vegetal foram produzidos nessa região até o Ministério Público Federal e Estadual exigirem do Ibama e do Inema a fiscalização de atividade ilegal de carvoejamento, isto é, a produção de carvão na região de Guanambi para a comercialização do carvão (Foto 1).

Foto 1- Forno para fazer carvão vegetal no município de palmas de Monte Alto.

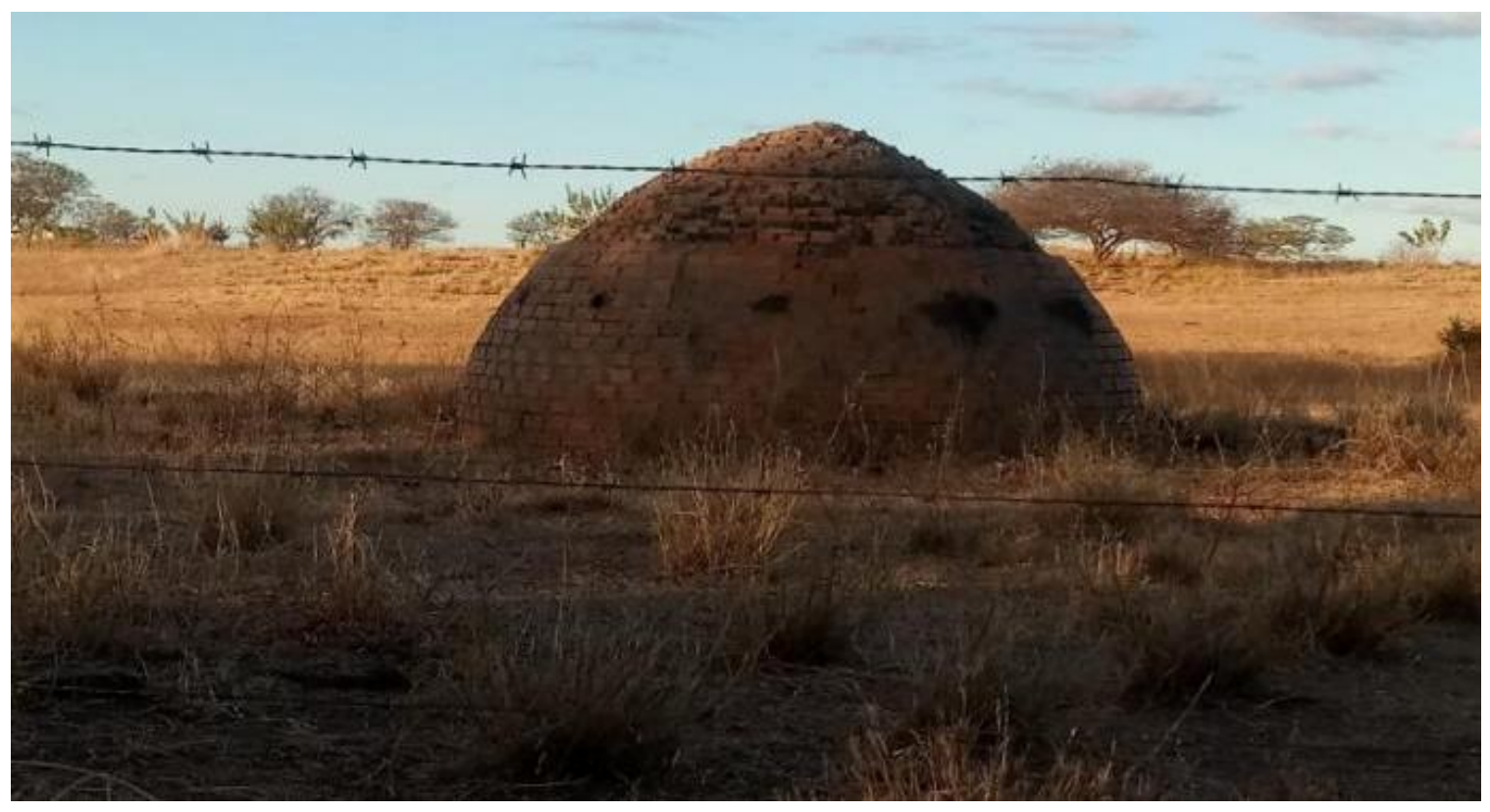

Fonte: Pesquisa de Campo, 2018. Foto: CASTRO, J. Julho, 2018.

O problema do desmatamento da área leste da bacia diz respeito à implantação do Parque Eólico ${ }^{5}$ na Serra Geral do Espinhaço no ano de 2011, abrangendo os municípios de Caetité, Guanambi e Pindaí. Concomitante à implantação do parque eólico, desencadeava a derrubada de extensas áreas de florestas, um corredor florestal sinuoso, obedecendo as curvas da região serrana (Foto 2).

\footnotetext{
${ }^{5}$ Parques eólicos com torres de 85 metros de altura e pás de 41 metros de comprimento, que exigiram a realização de fundações diretas com estaca raiz ou tirantes, além dos blocos de concreto sobre as fundações, Costa, (2012).
} 
Foto 2- Vista aérea do Parque Eólico de Guanambi, 2018.

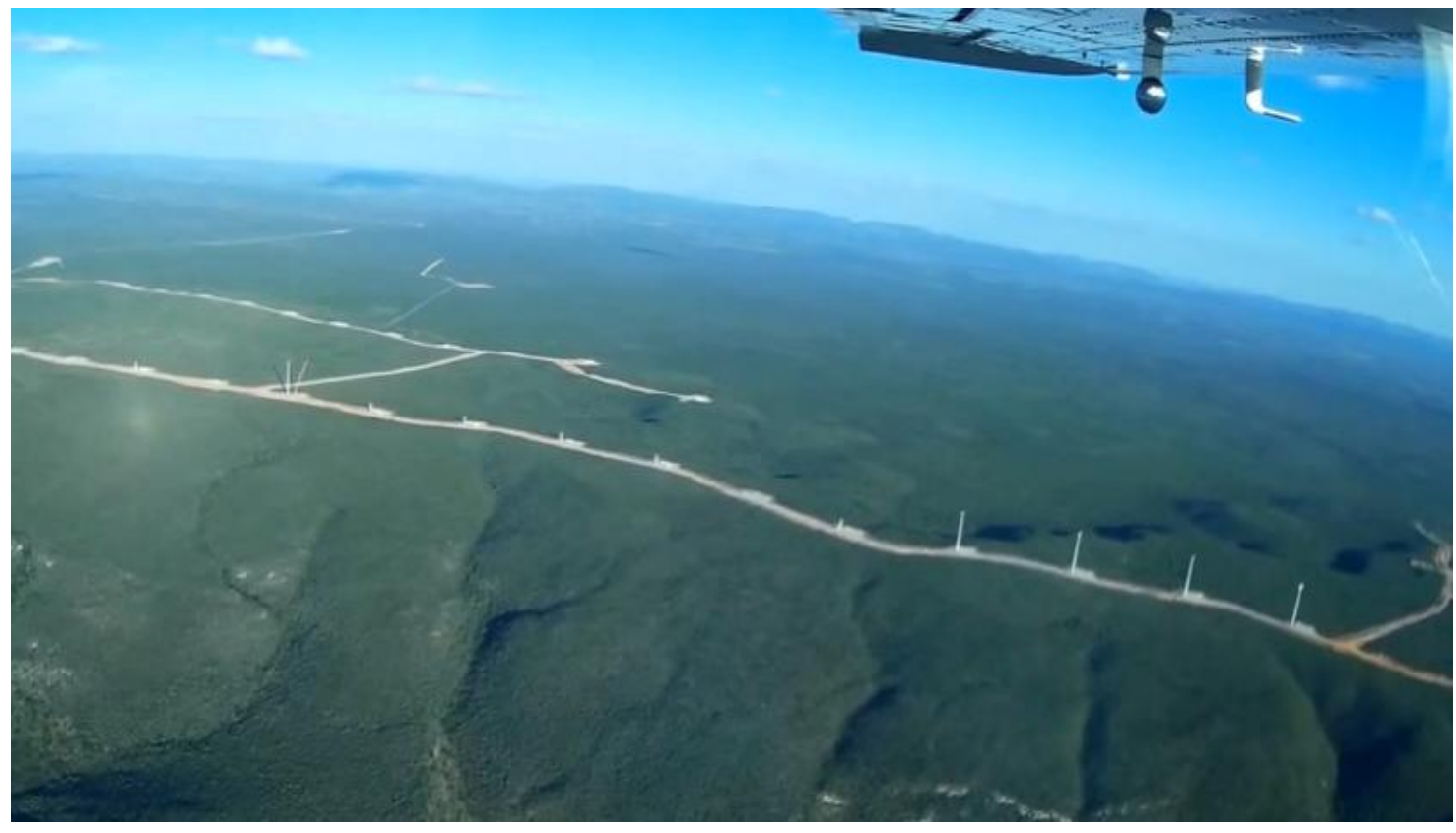

Fonte- Google, 2018.

Constata-se que além da retirada da cobertura vegetal, removeu ainda rampas de solos, grande volume de movimentação de terra, uma vez que os aclives e declives do terreno tiveram de ser removidos, para fazer a terraplanagem da obra. Conforme Costa (2012), a terraplanagem envolve a formação das vias de circulação, com 11 metros de largura cada uma com capacidade para receber a circulação de guindastes e carretas em mão dupla.

A abertura das vias circulatórias do parque eólico e implantação das torres causou vários processos impactantes negativos na área serrana: erosão, assoreamento, compactação, lixiviação. Segundo os moradores, aumentaram-se os ventos, diminuíram as chuvas e algumas espécies de aves e animais da fauna local.

Segundo Castro, é uma área de preservação ambiental, a nascente do rio Carnaíba de Dentro, apresenta "vegetação ciliar abundante e densa, árvores gigantescas no meio da floresta, próximo à cachoeira da Mangabeira, que é utilizada como fonte de lazer pelos moradores" (CASTRO, 2010, p.35). A fotografa do painel 1 faz uma comparação da cachoeira em períodos diferentes, em julho de 2018 e a segunda em janeiro de 2008, uma década entre as imagens e verifica-se que a natureza 
é o alvo da intervenção humana, responsável pela (des)organização do espaço e pela transformação do meio natural determinada pelo contexto histórico em que a sociedade está inserida.

Painel 1- Cachoeira da Mangabeira em períodos diferentes (2008 e 2018). Periodo seco e periodo Chuvoso
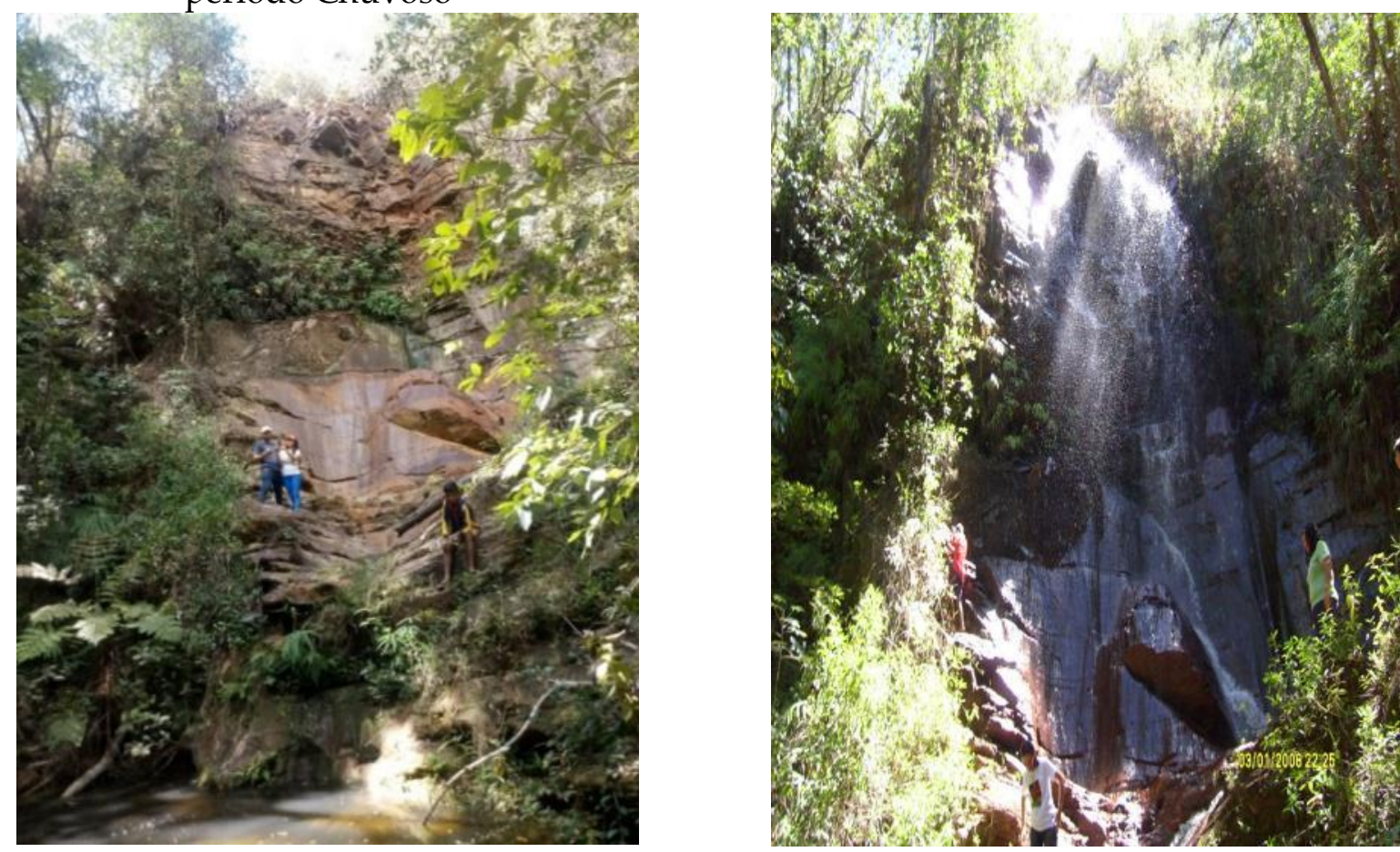

Fonte: Pesquisa de Campo, 2008 e 2018. Foto: CASTRO, J. Fevereiro,2008. Julho, 2018.

A relação sociedade-natureza é uma adaptação às exigências humanas, pois o ambiente é alterado pelas atividades humanas e o grau de alteração de um espaço, em relação a outro, é avaliado pelos seus diferentes modos de produção e/ou diferentes estágios de desenvolvimento da tecnologia (GUERRA e CUNHA, 1996, p. 340).

Outro agrave nas condições de uso e ocupação do solo da bacia do rio Carnaíba foi a construção da Ferrovia de Integração Oeste-Leste (FIOL), ferrovia com cerca de $1.500 \mathrm{~km}$ de extensão voltada para exportação, interligando o Norte (Tocantins), o Centro (Goiás) e o Nordeste (Bahia). A FIOL atravessa a área da bacia no sentido norte-noroeste-leste, com $10 \mathrm{~km}$ de extensão de linha férrea em construção, ela inicia numa área de depressão no município de Palmas de Monte Alto, contorna uma parte 
do rio Carnaíba de Dentro e depois segue o percurso na margem direita até atravessar a BR 030 em Guanambi e segue até Ceraíma.

O desmatamento das áreas que estão na trajetória de implantação da FIOL provocou a extração ou retirada de espécies vegetais nativas e dos solos, aterramento de rios e lagoas e desvios de seu curso natural, compactação do solo, alterações de comportamento dos animais silvestres, alterações no uso do solo e deslocamento de pessoas (Painel 2).

Painel 2-Diferentes estágios da Ferrovia de Integração Oeste-Leste em construção (Lote 5).
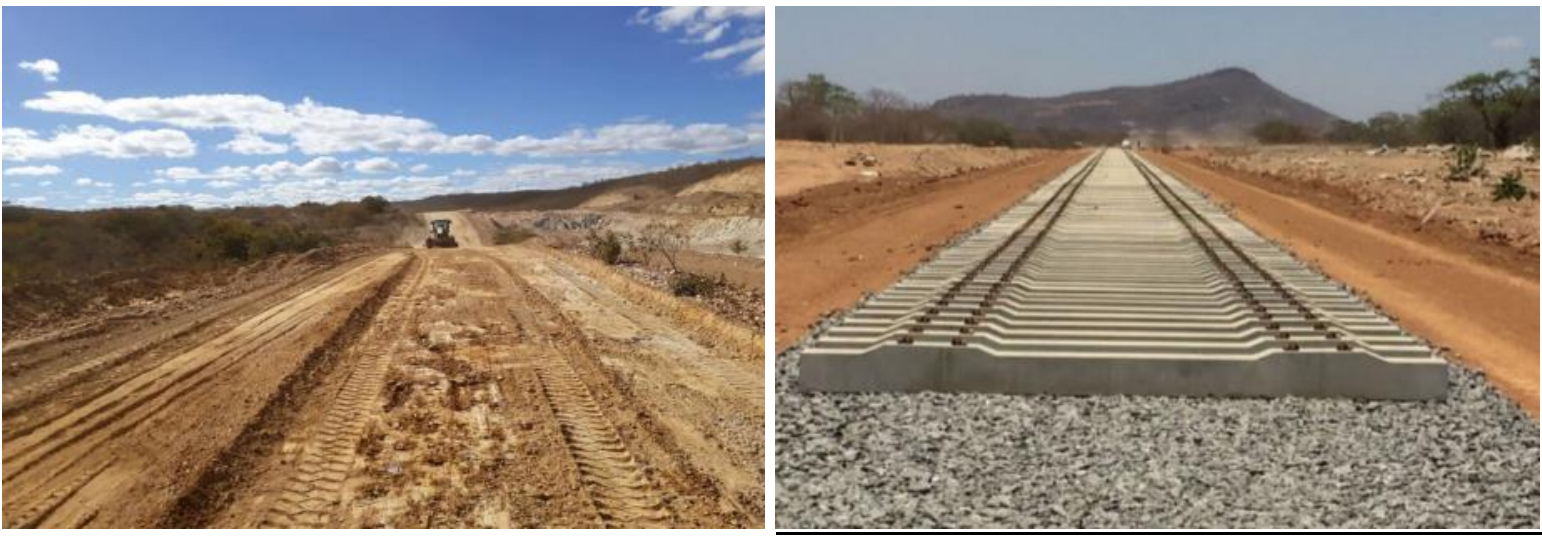

Fonte: https://www.facebook.com/FerrovoaOesteLeste. (out. 2020 )

Segundo Castro (2010), o desmatamento da mata ciliar da bacia do rio Carnaíba, a princípio foi para a agricultura familiar e pastagens, mais tarde cedeu espaço para a agricultura comercial e logo após esse cenário geográfico é transformado em função da exportação comercial de cunho interno e externo.

\section{Ocupação humana}

A ocupação humana da bacia do rio Carnaíba de Dentro na parte superior da bacia é pouco desenvolvida, a área edificada (urbanizada) aparece com mais frequência nas regiões de relevo aplainado, predominantemente na área central da bacia. O mapa de uso do solo e cobertura vegetal confirma a ocupação por áreas urbanas consolidadas com alta e média taxas de ocupação (Nucci, 1999) haja vista a grande área ocupada como as sedes municipais das cidades de Guanambi, Candiba e Pindaí. 
Embora, Guanambi sobressaia em relação às outras sedes municipais supracitadas, sua área edificada é de maior representatividade, uma vez que a expansão do espaço urbano provocou transformações espaciais devido o processo de urbanização com áreas em implantação de novos empreendimentos que revelam áreas de loteamentos com edificações modernas, condomínios fechados de alto padrão, condomínio empresarial, bairros populares com casa do Programa do Governo Federal Minha Casa Minha Vida, sistema de arruamento e áreas terraplenadas para indústrias, instituições e comércio.

De acordo com os indicadores dos municípios que compõem a bacia do rio Carnaíba de Dentro (Tabela 1), Guanambi possui $87 \%$ do seu território na área da bacia e apresenta uma taxa de urbanização $(79,4 \%)$ elevada, visto que $80 \%$ da população é urbana, e sua densidade demográfica de $66,2 \mathrm{hab} / \mathrm{km}^{2}$ retrata o perfil um município populoso.

Tabela 1- Indicadores dos municípios que compõem a bacia do rio Carnaíba de Dentro.

\begin{tabular}{|l|c|c|c|c|c|c|c|}
\hline Municipio & $\begin{array}{c}\text { Pop. } \\
\text { urbana }\end{array}$ & Pop. rural & Pop. total & $\begin{array}{c}\text { Área/bacia } \\
(\mathrm{em} \mathrm{km})\end{array}$ & $\begin{array}{c}\text { Área } \\
\left(\mathrm{em} \mathrm{km}^{2}\right)\end{array}$ & $\begin{array}{c}\text { Densidade } \\
\left(\mathrm{hab}^{\mathrm{k}} \mathrm{km}^{2}\right)\end{array}$ & $\begin{array}{c}\text { Urbani } \\
\text { zaçăo(\%) }\end{array}$ \\
\hline Caetité & 28.447 & 19.068 & 47.515 & 169 & $2.442,9$ & 21,5 & 59,9 \\
\hline Candiba & 7.725 & 5.485 & 13.210 & 425 & 433,6 & 35,1 & 58,5 \\
\hline Guanambi & 62.565 & 16.268 & 78.833 & 1134 & $1.296,7$ & 66,2 & 79,4 \\
\hline P. M. Alto & 9.832 & 10.943 & 20.775 & 491 & $2.524,9$ & 8,9 & 47,3 \\
\hline Pindai & 4.319 & 11.309 & 15.628 & 380 & 614,1 & 27,4 & 27,6 \\
\hline
\end{tabular}

Elaboração: CASTRO, J. Fonte: dados da SEI, http://www.sei.ba.gov.br (2019).

Em face das ocupações urbanas, Pereira (2013) aborda que Guanambi entre 2007 e 2012, provocada pelo crescimento da oferta de produtos comerciais e de serviços, apresenta grande expansão no setor habitacional, que se tornou alvo da especulação imobiliária. Essas ocupações, a partir de 2015 disseminou-se de forma não planejada 
sobretudo para áreas periurbanas, compondo manchas edificadas de baixa densidade o que demonstra alto grau de antropização no meio natural em área de risco.

No que se refere a área edificada de Candiba, município com 98\% do território na bacia, aponta uma taxa de urbanização de 58,5\% e uma população distribuída quase equiparada entre zona urbana e rural, e sua densidade demográfica de 35,1 hab $/ \mathrm{km}^{2}$, embora o município retrata-se não muito populoso.

Observa-se uma área urbana não consolidada com densidade média de habitações, onde ocorre a presença de espaços livres correspondentes a lotes ainda não ocupados por edificações, porém os terrenos vazios apresentam menor expressão em área comparativa aos lotes ocupados. A lagoa do Mocambo é uma área natural revitalizada e preservada no interior da cidade. Isso mostra que a interação da sociedade com a natureza no período de expansão da cidade, reconheceu e aproveitou as potencialidades naturais da lagoa para compor a beleza cênica da área urbana de Candiba.

No que diz respeito a Pindaí, sua área territorial correspondente à bacia é de $60 \%$, possui uma área urbana com uma taxa de urbanização de $27,6 \%$, sendo as edificações esparsas com loteamentos urbanos em processo inicial de ocupação. A população residente no município é predominante rural $(72 \%)$ e sua densidade demográfica de $27,4 \mathrm{hab} / \mathrm{km}^{2}$.

Os municípios extremos da bacia do rio Carnaíba de Dentro, Caetité (nascente) e Palmas de Monte Alto (foz) não apresentam área urbanizada no limite da bacia, são os municípios de maior área territorial, contudo apenas 7\% e 19\% respectivamente dos territórios estão em área da bacia.

O processo de ocupação humana na parte da nascente é restrito, em virtude do difícil acesso na área serrana, portanto a área edificada nessa região é quase nula. Ressalta-se, ainda, que o município de Caetité apresenta uma população de predominância urbana e densidade demográfica de 21,5 hab $/ \mathrm{km}^{2}$ (IBGE, 2010).

Palmas de Monte Alto, apesar de estar numa área plana, de maior acumulação de água nas áreas de baixadas, especialmente na região de desembocadura do rio 
Carnaíba de Dentro, apresenta uma densidade demográfica de 8,9 hab/ $\mathrm{km}^{2}$, devido à grande extensão territorial e pequena população. Apresenta uma taxa de urbanização de $47,3 \%$.

\section{Aterramento das Lagoas e das margens do rio Carnaíba de Dentro}

Do ponto de vista ambiental é histórico que o homem para satisfazer suas necessidades, tem provocado alterações ambientais, cria-se agressões ao ambiente decorrentes de um somatório de fatores, ligados à exploração dos recursos naturais, ao uso e ocupação desordenado do solo, a urbanização e ao crescimento da malha urbana sem planejamento e a expansão imobiliária em larga escala.

Uma série de problemas ambientais, como a geração de resíduos sólidos e efluentes, poluição do ar, da água e do solo, impermeabilização do solo; aterramentos de rios, córregos, lagoas; modificações nos ecossistemas são consequências da ocupação humana desordenada, principalmente, em uma bacia hidrográfica, que depende do equilíbrio entre seus elementos para ter uma qualidade ambiental.

A organização espacial de Guanambi é compreendida pela bacia do rio Carnaíba de Dentro e seus afluentes: Riacho Belém, e dos Brindes (da margem direita), o Poço do Magro (margem esquerda) e diversas lagoas naturais e áreas alagadas, com profundidade e dimensões variadas, que compõem o sistema integrado de drenagem e de acumulação de água pluvial, pois todas recebem água de chuvas.

De acordo com alguns entrevistados a cidade era um espelho d'água, rodeado por lagoas e drenado por riachos, tanto no limite do perímetro urbano quanto na parte interna, "tínhamos diversas lagoas, mas houve um processo muito forte de degradação e aterramento dessas lagoas, das 30 lagoas que tinha só restaram 7, com muita luta através do Ministério Público para que não acontecesse o aterramento" (Informação $\operatorname{verbal}^{6}$ ). Nascimento (2010), aborda que no perímetro urbano existem várias lagoas e córregos que servem de escoadouro das águas pluviais, muitas delas são margeadas por capins e tabuas e servem de depósito de lixo.

\footnotetext{
${ }^{6}$ Informação cedida por entrevista em julho de 2018.
} 
A despeito da importância dos recursos hídricos para a sobrevivência, nota-se que as lagoas referidas desapareceram, sofreram uma grave degradação ambiental, as áreas foram aterradas para suprir as demandas no setor habitacional e tornou-se o centro das atenções para a especulação imobiliária. Pereira (2013), assinala que as transformações nos setores produtivos da cidade aumentaram a gama de serviços oferecidos, e por isso,

houve uma grande expansão no setor habitacional, que se tornou alvo da especulação imobiliária. O fato de estar localizado numa área plana, ter passado por ampliação do perímetro urbano e recebido infraestrutura urbana do poder público, contribuiu para a atuação dos especuladores imobiliários, provocando a elevação dos preços dos terrenos na cidade. (PEREIRA, 2013, p. 13).

Observa-se que o crescimento do setor habitacional determinado pela especulação imobiliária por meio da expansão dos loteamentos em áreas aterradas em condomínios afastados do centro da cidade, com infraestrutura completa (rede de água, energia elétrica, asfalto) fortalece a política de vendas do setor imobiliário, que facilita o valor do empreendimento e aumenta a apropriação dos lotes sem conhecer dinâmica ambiental do terreno, causando graves impactos ambientais.

, sistematicamente registrava-se vários processos de aterramento.

Painel 3- Aterramento de uma lagoa localizada na BR-030 em Guanambi e outra na BR 122 em Guanambi, 2018.
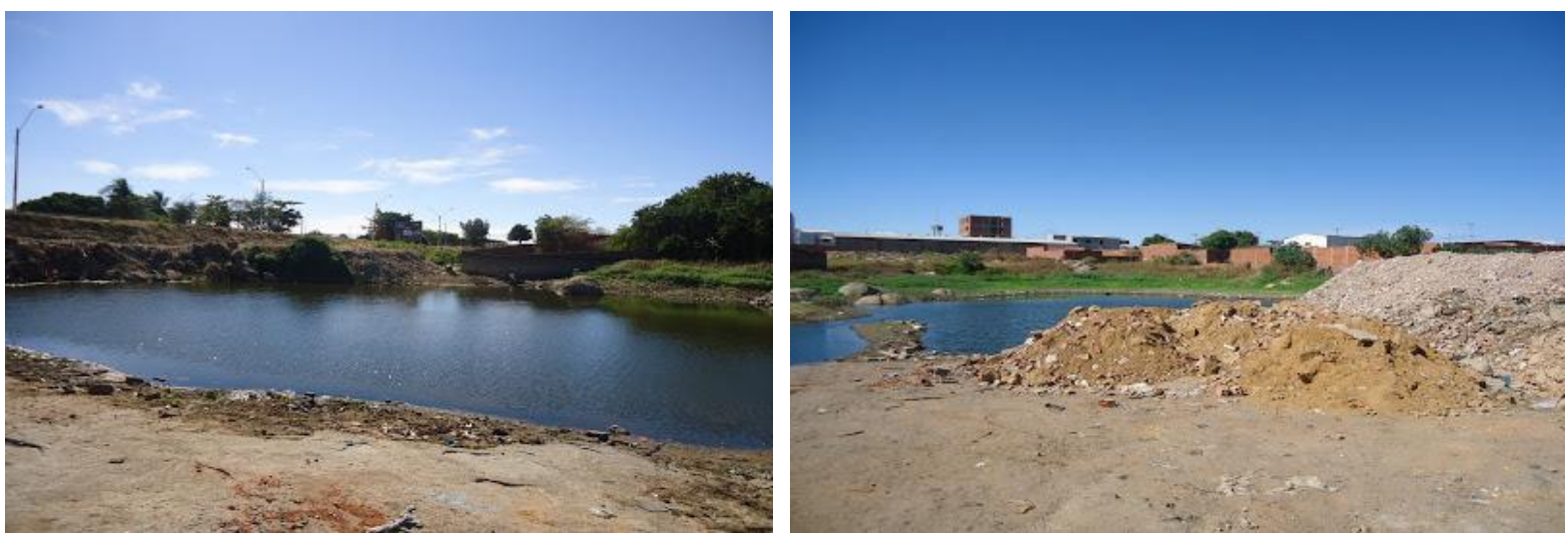

Fonte: Pesquisa de Campo, 2018. Foto: CASTRO, J. Out. 2018. 
Em relação as lagoas que, ainda, restam encontram-se complemente degradadas, com redução da capacidade de escoamento do sistema natural, assoreadas e poluídas devido ao lançamento de esgotos e lixo e aterramento, pois à medida que a pesquisa se desenvolvia

De acordo com as legislações ambientais municipais, essa ação é ato de desrespeito à ao Plano Diretor e ao Código de Defesa do Meio Ambiente de Guanambi, mas o poder público municipal tem respaldado esse processo de degradação e colaborado com a especulação imobiliária. Segundo o entrevistado J. B. do Inema, as lagoas estão sendo aterradas, mas precisa de licença assim como as outras lagoas, que foram aterradas sem a permissão. Antes não tinha a exigência da lei, mas atualmente é necessário cumprir a legislação e mesmo assim, a lagoa da Pedra do Leão (saída para Palmas de Monte Alto) está em processo de aterramento.

No que diz respeito a lagoa de João Amaral, localizada na zona norte da cidade, BR 030, está muito assoreada, a ponto de estar seca pela quantidade de terra no fundo, com queimada na lateral direita, o lixo em torno da lagoa é intenso, joga-se até lixo hospitalar. É uma área interna da cidade, no entanto é desprotegida, sem segurança e sem vigilância (Foto 16). Há uma disputa entre o dono da área da lagoa e a gestão municipal, que quer tomba-la como patrimônio público municipal e uma APP, todavia o dono quer aterrar a área e lotear, segundo moradores vizinhos, foram jogadas mil caçambas de terras para aterrá-la, porém o ministério público embargou e o Inema deu parecer favorável à manutenção da lagoa.

Apesar dos conflitos com problema judicial de posse, está lagoa já sofreu grave impacto ambiental desde a construção da BR 030 (1980), que dividiu a massa de água em duas partes, pois antes tinha uma estrada vicinal que passava apenas na ponta da lagoa.

No rol das lagoas, ainda existem 4 preservadas, as lagoas que pertencem aos clubes recreativos da cidade: Clube de Campo e Recreio Tênis Clube que não podem ser aterradas pois elas pertencem ao estado, são usadas como reservatório de água e 
lazer. Tem a lagoa do rio Carnaíba de Dentro, saída para Ceraíma, que segundo o entrevistado J.B não é uma lagoa, é um alargamento do rio, "um tanque com o braço do rio Carnaíba. O rio mudou o curso de lugar, antes ele passava na frente do posto e passava no castelinho que tem um lago artificial" (Informação verbal'7). E tem a lagoa do Parque da Cidade, construída a partir do alargamento do canal do Riacho Belém.

A partir da compreensão do processo de apropriação dos recursos ambientais, que ocorre nas margens das lagoas é possível observar um conjunto de problemas ambientais configurados pelo crescimento desordenado da cidade, e ocupação das margens dos rios e do aterramento de lagoas de forma irregular pela especulação imobiliária e da intensa atividade comercial às suas margens. Dessa forma, as lagoas demonstram sinais de insustentabilidade na sua capacidade de acumulação e na sua biodiversidade, face as alterações na qualidade e quantidade de suas águas.

A ocupação irregular nas margens dos rios na área da bacia do rio Carnaíba de Dentro é um impacto ambiental de grande abrangência e alta intensidade tanto no rio Carnaíba de Dentro quanto nos riachos Belém e dos Brindes, em consequência de projetos imobiliários que podem causar problemas ambientais sérios devido aos aterros que ocorreram com o Riacho dos Brindes e vem ocorrendo com o Riacho Belém.

Observa-se que esse riacho é receptor das águas pluviais de toda área urbana e a construção de edificações, a pavimentação de ruas, e a sua canalização, resultam na impermeabilização do solo que faz o volume de água aumentar e o canal fluvial obstruído, causa inundação.

Os problemas ambientais nas proximidades do Riacho Belém constituem fatores de influência para a degradação do mesmo, uma vez que o desmatamento é a “principal atividade lesiva ao meio ambiente e que faz parte da implantação dos empreendimentos imobiliários" (ARAUJO, 2001, p. 368), para execução de projetos imobiliários, como bairro residencial nobre, comercial e loteamentos de grande porte.

\footnotetext{
${ }^{7}$ Informação cedida por entrevista em agosto de 2018.
} 
Outro problema é a poluição gerada pelos resíduos sólidos jogados nas margens e no canal e pelo esgotamento sanitário que são lançados no riacho.

No que se refere ao rio Carnaíba de Dentro, constata-se que sua área de vazante foi assoreada devido ao desmatamento e a construção da rodovia Valdir Pires na década de 1990 que dividiu a área da vazante nivelando-a com a planície de inundação. Segundo Castro o "aterramento aplainou o canal, e este desapareceu no local, alagando toda a planície e mudando a geomorfologia e geometria hidráulica do rio" (CASTRO, 2010, p.38). Apesar da área ser plana, constatou-se que o canal do rio sofreu interferência humana, desviando-o para beneficiar-se de suas águas.

Os problemas ambientais urbanos nas margens do rio Carnaíba de Dentro constituem-se dos empreendimentos imobiliários, aterramento de lagoas, resíduos sólidos e esgotamento sanitário. O esgotamento sanitário, um dos maiores problemas ambientais urbanos da bacia, são lançados no rio e nos riachos, pois a cidade tem uma estação de tratamento de esgoto, que só recebe $45 \%$ do esgotamento sanitário. Segundo um entrevistado, a ETE faz o trabalho,

de jogar a água dentro do rio com $98 \%$ de aproveitamento da qualidade e a natureza faz os outros $2 \%$, mas infelizmente como ainda foi feito uma rede de esgoto paralela ao rio Carnaíba de Dentro e o riacho Belém, há vazamentos e o esgotamento sanitário fica a céu aberto, um perigo para a população pois a água que vem do São Francisco pode estar contaminada. Guanambi precisa avançar logo e concluir $100 \%$ do esgotamento sanitário, para que todo o esgoto seja tratado e arremessado no rio Carnaíba de Dentro de forma a garanti a qualidade e sustentabilidade da água. (Informação verbal ${ }^{8}$ ).

Nesse sentido, percebe-se que Guanambi precisa garantir o esgotamento sanitário para sanar parte dos problemas ambientais e fiscalizar o crescimento planejado pela especulação imobiliária e pela apropriação indevida dos moradores. A planície aluvial onde acontece o encontro do rio Carnaíba de Dentro com o riacho Belém fica próximo a Faculdade Integradas do Pitágoras (FIP), que foi construída em 2017 nessa planície aterrada que deu origem a um novo loteamento, onde "vai fazer

\footnotetext{
${ }^{8}$ Informação cedida por entrevista em agosto de 2018.
} 
um pequeno parque e uma ponte do outro lado do Carnaíba, vão deixar a área de APP de $8 \mathrm{~m}$, já usando a vegetação natural que já existe" (Informação verbal ${ }^{9}$ ).

Mapa 3- Problemas socioambientais da bacia hidrografica do rio Carnaíba de Dentro - BA

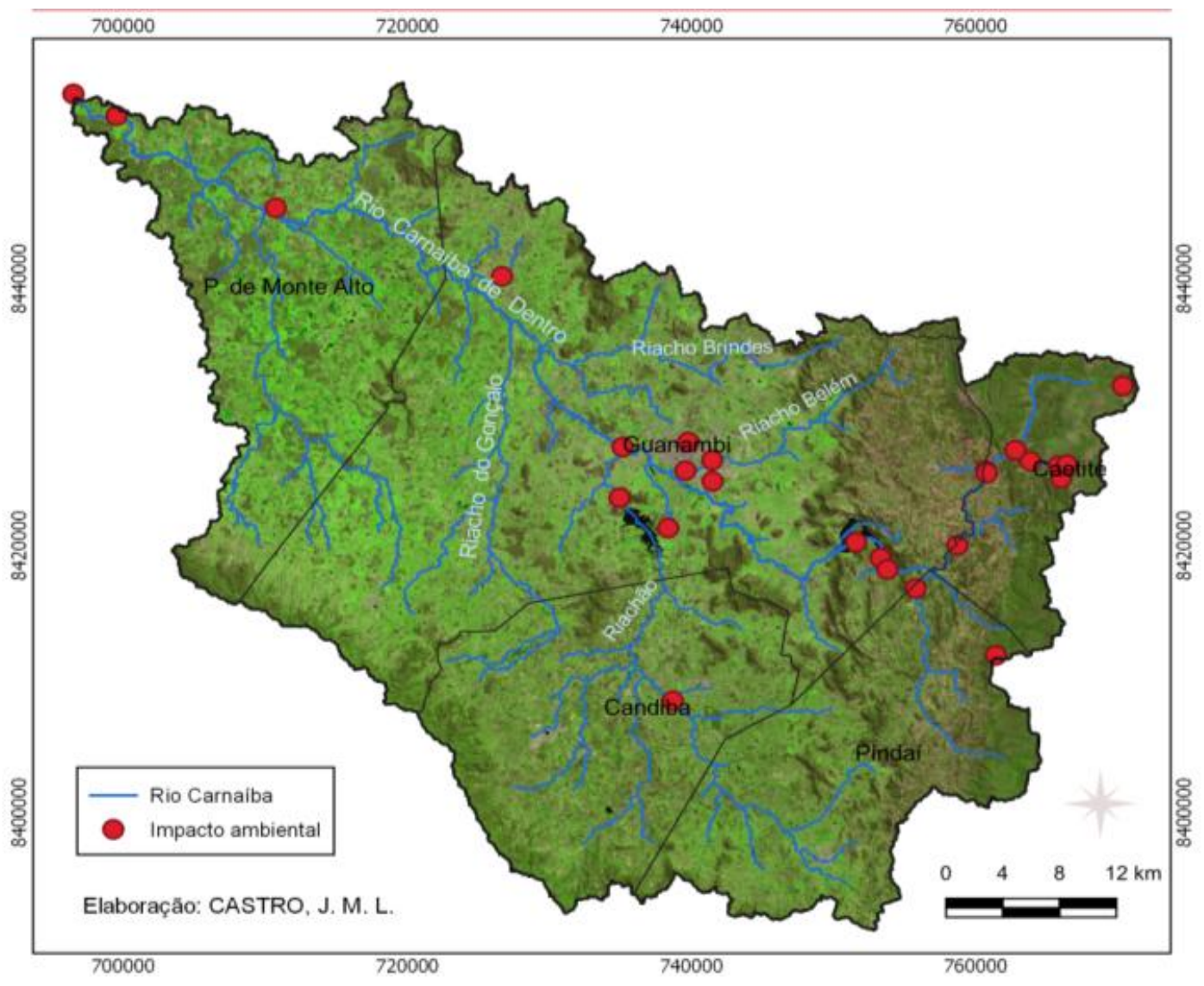

Fonte: Bahia, 2010. Elaboração: CASTRO, J. Setembro, 2018.

Os problemas socioambientais da bacia hidrografica do rio Carnaíba de Dentro

- BA retrataram inferências da intervenção humana para a degradação ambiental da bacia, no caso uso do solo, como o desmatamento, represamento da água por meio da construção de reservatórios, resíduos sólidos e efluentes urbanos, queimadas, poluição do ar, água e solo, esgotamento sanitário, exploração mineral, uso de agrotóxicos, aterramentos de rios e lagoas, ocupação humana irregular e desordenada nas margens dos rios, compactação e impermeabilização do solo por meio da construção da ferrovia, parque eólico e barragem de rejeitos da Bahia Mineração (BAMIN), como mostra o mapa 3.

\footnotetext{
${ }^{9}$ Informação cedida por entrevista em agosto de 2018.
} 
De forma relevante para toda a área da bacia, o desmatamento e consequentemente o assoreamento, é um problema ambiental de toda a bacia em consequência do solo exposto emanado pela retirada da cobertura vegetal, que cede espaço para a pecuária e a agricultura que juntas promoveram profundas modificações nas paisagens das áreas de planícies e depressões da bacia, visto que a implantação das pastagens e lavouras agricultáveis ocasionou a retirada da vegetação original da caatinga, no município de Guanambi, Candiba e Palmas de Monte Alto.

Dentre os principais problemas socioambientais da bacia hidrográfica do rio Carnaíba de Dentro, correlacionados ao meio urbano e aos reservatórios de água destacam-se alterações oriundas de aterramento de lagoas; resíduos sólidos urbanos de esgotos domésticos, industriais e hospitalares; efluentes líquidos; lixo disposto às margens dos rios e rodovias; canalização e modificação do rio e de riachos.

\section{Considerações finais}

Para compreender as metamorfoses socioespaciais da bacia do rio Carnaíba de Dentro faz-se necessário avaliar a intensidade da ação humana por meio dos impactos socioambientais provocados por meio da exploração desordenada dos recursos naturais, desde meados do século $X X$, quando sucede $\mathrm{o}$ crescimento $\mathrm{e} o$ desenvolvimento econômico dos municípios em toda a unidade territorial da bacia.

O processo de desmatamento da bacia do rio Carnaíba de Dentro, apesar de iniciado desde o período da colonização da região, ainda no século XVIII com o adentramento da pecuária extensiva, intensificou-se em meados do século $X X$. A pecuária e a agricultura juntas promoveram profundas modificações nas paisagens das áreas de planícies e depressões da bacia, visto que a implantação das pastagens e lavouras agricultáveis ocasionou a retirada da vegetação original da caatinga, no município de Guanambi, Candiba e Palmas de Monte Alto.

Os efeitos da agropecuária sobre o meio natural dependem da intensidade e do grau da alteração provocada no solo e na vegetação. Além dessa problemática significativa de abrangência territorial associada diretamente ao desmatamento, os 
municípios que constituem a bacia apresentam uma série de outros problemas socioambientais que se exprimem de maneira pontual, por vezes também pela retirada da cobertura vegetal.

Percebe-se que o rio espelha as consequências das atividades humanas desenvolvidas e estas, proporcionam a alteração das características naturais da bacia e a degradação ambiental, portanto apontam a necessidade de políticas públicas eficientes e atuação da sociedade civil organizada para solucionar ou atenuar os problemas detectados.

\section{Referências}

AB'SABER, A. N. Os domínios de natureza no Brasil - Potencialidades Paisagísticas. São Paulo Ateliê Editorial. 2003.

ARAUJO, J. Algumas considerações acerca do município de Palmas de Monte Alto, 2012. In: In: SILVA, Joaquim P. Territórios e ambientes da serra de Monte Alto. Vitória da Conquista: Edições UESB, 2012.

BOMFIM, I. A. S. A degradação do Riacho Belém em Guanambi - BA: uma análise ambiental urbana. In: CASTRO, J. M. L.; BOMFIM, I. A. S.; NASCIMENTO, G. A. S. Bacias hidrográficas de Guanambi: uso, ocupação e conservação - rio Carnaíba de Dentro, riacho Belém e zoneamento urbano das áreas verdes. Brasília-DF: Exlibris, 2010.

CASTRO, J. M. L. Análise dos aspectos geoambientais da bacia do rio Carnaíba de Dentro no município de Guanambi. In: CASTRO, J. M. L.; BOMFIM, I. A. S.; NASCIMENTO, G. A. S. Bacias hidrográficas de Guanambi: uso, ocupação e conservação - rio Carnaíba de Dentro, riacho Belém e zoneamento urbano das áreas verdes. Brasília-DF: Exlibris, 2010.

COSTA, J. C. L. 2012. Blog do Latinha, 2018.

DREW, D. Processos interativos homem-meio ambiente. 8. ed. Rio de Janeiro: Bertrand Brasil, 2011.

GUERRA, A. J. T.; CUNHA, S. B. da. (Org). Geomorfologia e meio ambiente. Rio de Janeiro: Bertrand Brasil, 1996.

IBGE (Instituto Brasileiro de Geografia e Estatística) Censo demográfico 2010.

Disponível em: http://www.ibge.gov.br/home/. Acesso entre jun. e out. de 2018. 
NASCIMENTO, G. A. S. Análise socioambiental das áreas verdes do espaço urbano de Guanambi. In: CASTRO, J. M. L.; BOMFIM, I. A. S.; NASCIMENTO, G. A. S. Bacias hidrográficas de Guanambi: uso, ocupação e conservação - rio Carnaíba de Dentro, riacho Belém e zoneamento urbano das áreas verdes. Brasília-DF: Exlibris, 2010.

NUCCI, J. C. Análise sistêmica do ambiente urbano, adensamento e qualidade ambiental. Ciências Biológicas e do Ambiente, São Paulo, v. 1, n. 1, p. 73-88, 1999.

PEREIRA, S. R. Guanambi: centralidade, rede urbana e dinâmica regional no centrosul baiano. Salvador, 2013. Dissertação de mestrado. Disponível em: https://repositorio.ufba.br/ri/bitstream/ri/20146/1/Sofia_Reboucas_Neta_Pereira_Disser tacao.pdf. Acessado em 15.01.2019.

Contribuição dos autores: Jane Mary Lima Castro; Elaboração, discussão dos resultados, pesquisa bibliográfica, revisão do texto Meirilane Rodrigues Maia : Supervisão, análise final dos resultados e revisão do texto 